\title{
Neurological Recovery in Two Patients with Cauda Equina Syndrome Secondary to L5 Lumbar Spine Giant Cell Tumour after Treatment with Denosumab without Surgery
}

\author{
Simret Singh Randhawa, Angel Khor Nee Kwan, \\ Chee Kidd Chiu, Chris Yin Wei Chan, Mun Keong Kwan \\ Department of Orthopaedic Surgery, National Orthopaedic Centre of Excellence for Research and Learning, \\ University of Malaya, Kuala Lumpur, Malaysia
}

\begin{abstract}
We report two patients with cauda equina syndrome (CES) secondary to L5 giant cell tumour (GCT) who achieved good neurological recovery after treatment with denosumab without surgery. The first patient was a 26-year-old man with L5 GCT causing CES who regained bowel and urinary control, muscle power improvement from grade 2 to grade 4 and Oswestry disability index (ODI) improvement from 48 to 23 after denosumab treatment. The second patient was a 25-year-old woman with L5 GCT causing CES who regained bowel and urinary control, muscle power improvement from grade 0 to grade 4 and ODI improvement from 42 to 20 after denosumab treatment. The usage of denosumab in the treatment of patients with CES due to GCT allows potential neurological recovery without any surgical intervention. If surgery is not contraindicated, more time is obtained to prepare the patient preoperatively to attain safer surgery and to achieve complete tumour clearance.
\end{abstract}

Keywords: Denosumab; Giant cell tumour; Cauda equina syndrome; Spine; Oncology

\section{Introduction}

Giant cell tumours (GCTs) of the spine are rare. The majority of spinal GCTs occurs in the sacrum [1]. Patients with GCT of the spine causing neurological compromise can be difficult to manage. Urgent surgery will allow decompression of the neural structures but increase the risk of potential operative complications and inadequate clearance. Delay in surgical intervention may worsen the neurological prognosis. We report two patients presenting with cauda equina syndrome secondary to L5 GCT who achieved good neurological recovery after treatment with denosumab without surgery.

\section{Case Reports}

\section{Case 1}

A 26-year-old man complained of worsening axial low back pain for a month. It was associated with progressive weakness of both ankle and toes for a week before presenting with cauda equine syndrome. Power of the ex-

\footnotetext{
Received Feb 29, 2016; Revised Mar 14, 2016; Accepted Mar 15, 2016

Corresponding author: Chris Yin Wei Chan

Department of Orthopaedic Surgery, National Orthopaedic Centre of Excellence for Research and Learning,

Faculty of Medicine, University Malaya, 50603 Kuala Lumpur, Malaysia

Tel: +60128830301, Fax: +60379494642, E-mail: chrnat01@yahoo.com
} 
tensor hallucis longus (L5) was grade 2 and ankle plantar flexion (S1) was grade 4. Anal tone was lax with absent perianal sensation. Blood investigations were normal. Computed tomography (CT) and magnetic resonance (MR) scans showed a large extradural mass located dorsal and extending to the left pedicle of the L5 vertebra with destruction of L5 vertebral body and cauda equina compression at L5 level (Fig. 1). Transpedicular core needle biopsy confirmed the diagnosis of GCT. He was started on denosumab $120 \mathrm{mg}$ administered subcutaneously on days $1,8,15$, and 43 , and monthly thereafter. After 2 weeks of treatment he had regained full bowel and urinary control, muscle power grade of 4 to 5 with the ability to walk using walking frame and his Oswestry disability index (ODI) improved from 48 to 23 (Table 1 ). There were no denosumab related adverse reactions.

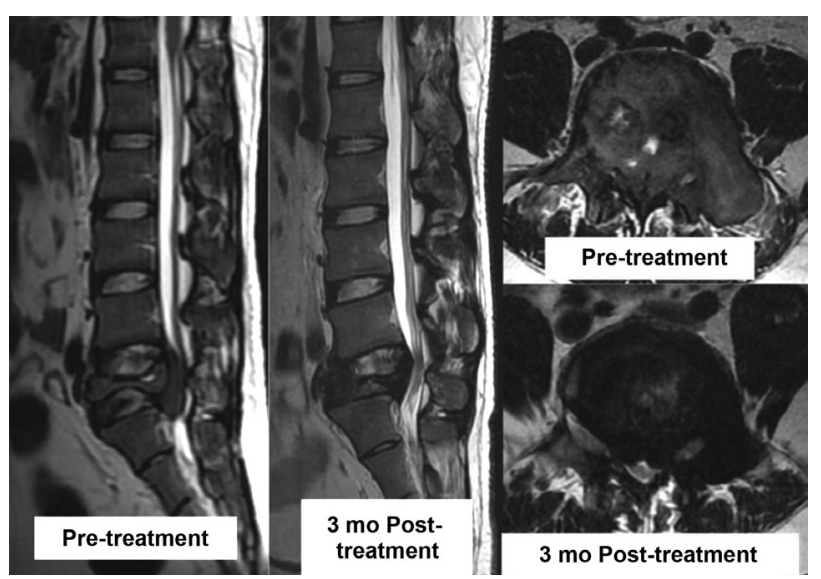

Fig. 1. Pretreatment and 3 months posttreatment magnetic resonance imaging of case 1 showed reduction in tumour mass and hypointensity of the tumour tissue in T2-weighted images.

\section{Case 2}

A 25-year-old woman complained of severe low back pain associated right sided sciatica for 2 months. She presented with acute ankle and toes weakness with loss of bladder and bowel control prior to admission. Her anal tone was lax with loss of perianal sensation. Power of the extensor hallucis longus (L5) was grade 0 and ankle plantar flexion (S1) was grade 2. Blood investigations were normal. CT and MR scans revealed a large extradural mass located dorsal and extending to the right pedicle of L5 vertebra with vertebra plana of L5 causing significant neural structure compression at L5 level (Fig. 2). MR imaging further revealed a hypointense signal on both $\mathrm{T} 1$ and $\mathrm{T} 2$-weighted images with contrast enhancement. Transpedicular core needle biopsy of L5 confirmed the diagnosis of GCT. Similar to the previous case, she was started on subcutaneous

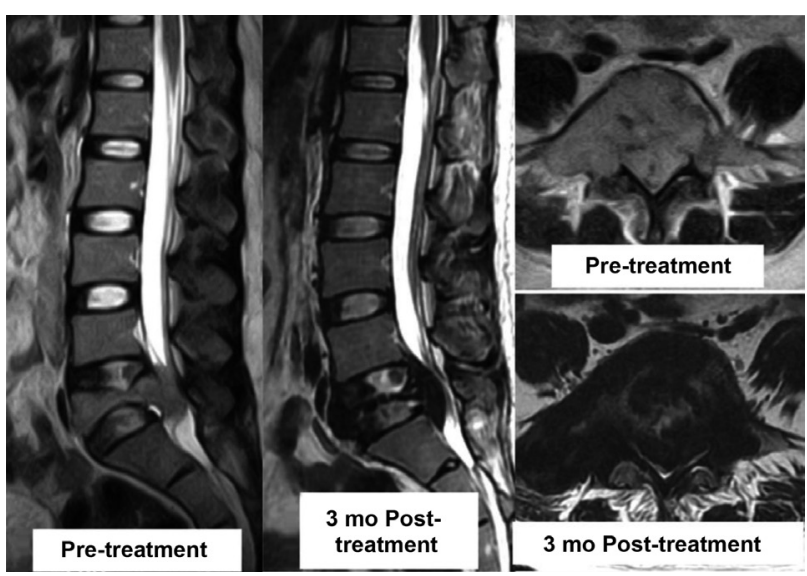

Fig. 2. Pretreatment and 3 months posttreatment magnetic resonance imaging of patient 2 showed similar reduction in tumour mass and hypointensity of the tumour tissue posttreatment.

Table 1. Neurological progress chart for case 1

\begin{tabular}{|c|c|c|c|c|c|c|c|c|c|c|c|}
\hline \multirow{3}{*}{$\begin{array}{l}\text { Treament } \\
\text { duration }\end{array}$} & \multicolumn{4}{|c|}{ Right } & \multicolumn{4}{|c|}{ Left } & \multirow{3}{*}{ Anal tone } & \multirow{3}{*}{$\begin{array}{l}\text { Perianal } \\
\text { sensation }\end{array}$} & \multirow{3}{*}{ ODI } \\
\hline & \multicolumn{2}{|c|}{ Motor } & \multicolumn{2}{|c|}{ Sensory $(\%)^{a}$} & \multicolumn{2}{|c|}{ Motor } & \multicolumn{2}{|c|}{ Sensory $(\%)^{a)}$} & & & \\
\hline & L5 & $\mathrm{S} 1$ & L5 & S1 & L5 & S1 & L5 & S1 & & & \\
\hline Pretreatment & 2 & 4 & 70 & 70 & 2 & 4 & 70 & 70 & Absent & Absent & 48 \\
\hline 2 weeks & 4 & 4 & 40 & 40 & 4 & 4 & 40 & 40 & Present & Present & 25 \\
\hline 6 weeks & 4 & 5 & 10 & 10 & 4 & 5 & 10 & 10 & Present & Present & 20 \\
\hline 3 months & 4 & 5 & 5 & 5 & 4 & 5 & 5 & 5 & Present & Present & 23 \\
\hline
\end{tabular}

ODI, Oswestry disability index.

a) Reduction of sensation, $100 \%=$ no sensation, $0 \%=$ normal. 
Table 2. Neurological progress chart for case 2

\begin{tabular}{|c|c|c|c|c|c|c|c|c|c|c|c|}
\hline \multirow{3}{*}{$\begin{array}{l}\text { Treament } \\
\text { duration }\end{array}$} & \multicolumn{4}{|c|}{ Right } & \multicolumn{4}{|c|}{ Left } & \multirow{3}{*}{ Anal tone } & \multirow{3}{*}{$\begin{array}{l}\text { Perianal } \\
\text { sensation }\end{array}$} & \multirow{3}{*}{ ODI } \\
\hline & \multicolumn{2}{|c|}{ Motor } & \multicolumn{2}{|c|}{ Sensory $(\%)^{a)}$} & \multicolumn{2}{|c|}{ Motor } & \multicolumn{2}{|c|}{ Sensory $(\%)^{a)}$} & & & \\
\hline & L5 & S1 & L5 & S1 & L5 & S1 & L5 & S1 & & & \\
\hline Pretreatment & 2 & 0 & 70 & 70 & 2 & 2 & 70 & 70 & Absent & Absent & 42 \\
\hline 2 weeks & 2 & 4 & 50 & 50 & 3 & 4 & 50 & 50 & Present & Present & 28 \\
\hline 6 weeks & 4 & 5 & 30 & 30 & 4 & 5 & 30 & 30 & Present & Present & 25 \\
\hline 3 months & 4 & 5 & 10 & 10 & 4 & 5 & 10 & 10 & Present & Present & 20 \\
\hline
\end{tabular}

ODI, Oswestry disability index.

a) Reduction of sensation, $100 \%=$ no sensation, $0 \%=$ normal.

denosumab $120 \mathrm{mg}$ on days $1,8,15$, and 43 , with monthly doses thereafter. She had good neurological recovery with improvement in ODI (Table 2). There were no denosumab related adverse reactions.

\section{Discussion}

GCT of bone is a rare but locally aggressive osteolytic tumour which composed of osteoclast-like giant cells with their precursors that express receptor activator of nuclear factor $\mathrm{kB}$ (RANK) and mononuclear stromal cells that express receptor activator of nuclear factor $\mathrm{kB}$ ligand (RANKL), a key mediator of osteoclast activation $[2,3]$. The aggressive bony destruction in GCT is mediated by RANKL. Furthermore, giant cells of GCT express significantly more RANK compared to the giant cells in other bony lesions (e.g., chondroblastoma, aneurysmal bone cyst and metastatic giant cell tumours) [4].

Denosumab is a monoclonal antibody (IgG2) that works by binding with high affinity and specificity to RANKL. It prevents RANKL from binding to RANK on the surface of osteoclast precursors and osteoclasts, which inhibits osteoclast differentiation, activation, maturation and survival $[5,6]$. Consequently, denosumab inhibits osteoclast mediated-bone destruction and suppresses osteolytic activity [7-10].

The response of GCTs to denosumab had been reported in the literature. Thomas et al. [8] conducted an open label phase 2 trial involving 37 patients with histologically confirmed GCT, and found that $86 \%$ had a tumour response defined as elimination of at least $90 \%$ giant cells or no radiological progression. This was supported by the findings of Branstetter et al. [11] who analysed the histology of GCT in a phase 2 study of denosumab, showing more than $90 \%$ elimination of giant cells in tumour stromal cells. Chawla et al. [12] reported the interim safety and efficacy of denusumab in an open label multi-centre study involving 29 centres with 282 patients and found that $96 \%$ in the surgically unsalvageable group had stable disease without progression. Girolami et al. [13] reported that denosumab treatment led to a significant reduction of the GCT proliferative index and tumour angiogenesis. Ueda et al. [14] reported that the proportion of patients with an objective tumour response was $88 \%$. Mattei et al. [15] reported a patient diagnosed with cervical C2 vertebrae GCT who had no recurrence 26 months after stabilisation surgery without excision with denosumab. However, Mak et al. [16] found that denosumab treatment led to obliteration of the giant cells; however, once the GST was no longer exposed to denosumab, the stromal cells would continue to proliferate but at a slower rate. Despite growing evidence that denosumab can arrest or slow GCT growth, none of the aforementioned reports described its usage for patients who present with acute paralysis or cauda equina syndrome caused by the tumour.

GCT of the L5 vertebrae is not common. Boriani et al. [17] reported had two L5 GCT in a review of 49 patients. Surgery to achieve complete excision of L5 GCT is challenging and the risks of intraoperative complications are high. Shimada et al. [18] documented excessive blood loss of $3.7 \mathrm{~L}$ and $6.9 \mathrm{~L}$ in two patients who underwent GCT excision, despite preoperative embolization of the tumour. In the latter case, the excision was not completed due to massive bleeding from the iliolumbar veins. Traditionally, a patient that presents with cauda equina syndrome secondary to GCT should be treated with emergency sur- 
gical decompression. However, both the aforementioned patients both demonstrated rapid clinical improvement within several days following commencement of denosumab therapy. This guided us in administering denosumab as a neo-adjuvant therapy.

We report two patients with cauda equine syndrome due to L5 GCT who achieved neurological recovery with denosumab treatment without surgical decompression. Both patients had muscle power, sensory, urinary and anal sphincter recovery, and their ODI improved with denosumab treatment (Tables 1, 2). Radiologically MR scan revealed shrinkage of the tumours (Figs. 1, 2). The potential advantage of this approach are better planning of the definitive surgical excision of the tumour, smaller tumour bulk and less bleeding during the definitive surgery. Denosumab has not been accepted as a definitive therapy for GCT. In cases of GCT that present with neurological emergency, denosumab can 'buy time' while definitive surgery is planned. This approach can also reduce the morbidity of the definitive surgery.

The usage of denosumab in the treatment of patients with cauda equina syndrome due to GCT may be a useful option. It allows potential neurological recovery without any surgical intervention. If surgery is not contraindicated, more time is obtained to prepare the patient preoperatively to attain safer surgery and to achieve complete tumour clearance.

\section{Conflict of Interest}

No potential conflict of interest relevant to this article was reported.

\section{References}

1. Murphey MD, Andrews CL, Flemming DJ, Temple HT, Smith WS, Smirniotopoulos JG. From the archives of the AFIP. Primary tumors of the spine: radiologic pathologic correlation. Radiographics 1996; 16:1131-58.

2. Roux S, Amazit L, Meduri G, Guiochon-Mantel A, Milgrom E, Mariette X. RANK (receptor activator of nuclear factor kappa B) and RANK ligand are expressed in giant cell tumors of bone. Am J Clin Pathol 2002;117:210-6.

3. Atkins GJ, Kostakis P, Vincent C, et al. RANK expression as a cell surface marker of human osteoclast precursors in peripheral blood, bone marrow, and giant cell tumors of bone. J Bone Miner Res 2006;21: 1339-49.

4. Won KY, Kalil RK, Kim YW, Park YK. RANK signalling in bone lesions with osteoclast-like giant cells. Pathology 2011;43:318-21.

5. Xu SF, Adams B, Yu XC, Xu M. Denosumab and giant cell tumour of bone-a review and future management considerations. Curr Oncol 2013;20:e442-7.

6. Hanley DA, Adachi JD, Bell A, Brown V. Denosumab: mechanism of action and clinical outcomes. Int J Clin Pract 2012;66:1139-46.

7. Thomas DM, Skubitz KM. Giant cell tumour of bone. Curr Opin Oncol 2009;21:338-44.

8. Thomas D, Henshaw R, Skubitz K, et al. Denosumab in patients with giant-cell tumour of bone: an openlabel, phase 2 study. Lancet Oncol 2010;11:275-80.

9. Lipton A, Jacobs I. Denosumab: benefits of RANK ligand inhibition in cancer patients. Curr Opin Support Palliat Care 2011;5:258-64.

10. Brodowicz T, Hemetsberger M, Windhager R. Denosumab for the treatment of giant cell tumor of the bone. Future Oncol 2015;11:1881-94.

11. Branstetter DG, Nelson SD, Manivel JC, et al. Denosumab induces tumor reduction and bone formation in patients with giant-cell tumor of bone. Clin Cancer Res 2012;18:4415-24.

12. Chawla S, Henshaw R, Seeger L, et al. Safety and efficacy of denosumab for adults and skeletally mature adolescents with giant cell tumour of bone: interim analysis of an open-label, parallel-group, phase 2 study. Lancet Oncol 2013;14:901-8.

13. Girolami I, Mancini I, Simoni A, et al. Denosumab treated giant cell tumour of bone: a morphological, immunohistochemical and molecular analysis of a series. J Clin Pathol 2016;69:240-7.

14. Ueda T, Morioka H, Nishida Y, et al. Objective tumor response to denosumab in patients with giant cell tumor of bone: a multicenter phase II trial. Ann Oncol 2015;26:2149-54.

15. Mattei TA, Ramos E, Rehman AA, Shaw A, Patel SR, Mendel E. Sustained long-term complete regression of a giant cell tumor of the spine after treatment with denosumab. Spine J 2014;14:e15-21.

16. Mak IW, Evaniew N, Popovic S, Tozer R, Ghert M. A translational study of the neoplastic cells of giant cell tumor of bone following neoadjuvant denosumab. J 
Bone Joint Surg Am 2014;96:e127.

17. Boriani S, Bandiera S, Casadei R, et al. Giant cell tumor of the mobile spine: a review of 49 cases. Spine (Phila Pa 1976) 2012;37:E37-45.
18. Shimada Y, Hongo M, Miyakoshi N, et al. Giant cell tumor of fifth lumbar vertebrae: two case reports and review of the literature. Spine J 2007;7:499-505. 